\title{
Personality Traits and Professional Future Anxiety among Practicing and Non-practicing Students of Sports Activities
}

\section{*Ahmed Abdallah Mohamed El-Roby}

Assistant Professor of Physical Education Faculty, Port Said

\section{Introduction}

Personality study has currently occupied an important place in sports psychology studies, through perceiving human behavior as a result of personal factors and the attributes it characterized by, working as an integrated unit. Physical activity provides many opportunities for social and moral formation of the individual. It builds the social characteristics that support one's life, such as self-control, cooperate with others, pride of belonging to the group, and sincerity to it. All these, in addition to other social and moral qualities that have significant effect on personality development and identify a clear vision for the future, which one seeks to achieve and identify his objectives. The sports movement is only a social movement that is integrated with each other and the community. (15:23)

There is no doubt that thinking and fearing of the future are of things that have not only become a concern or thought acquiring young people's mind, but thinking and predicting the future have also become among things that concern the civilized communities and peoples, who are trying to occupy their position at the global, international map. The today's youths are the future and tomorrow's men who think largely in the future and concern about it. The researcher found that the majority of students have anticipation and fear of the future. In order to identify these items, the research has become significant to determine the athletes' personality traits from non-athletes and identify the similarities and differences between them and the level of future anxiety to help them and highlight the role of sports activities, according to the distinctive characteristic of athletes.

\section{Research Problem}

Sports personality is characterized by collective action, overlapping with the society components, and interacting with surrounding environment. Psychological studies has expanded in studying the athlete to explore all things hidden in this social personality characterized by activity and movement. The mind preoccupation of professional future is of the most important things that haunt many of the young generations. This is due to a lot of life, living, and professional changes that has become occupying a large portion of young people thinking, from the selection of study major at the university level to looking for a job in the future and other requirements of life. Through the work of researcher as a lecturer, executive director, and the founder of the Arab Academy for Maritime Studies in Jeddah, Saudi Arabia, noticing that there is professional disciplines new to the nomadic environment and culture of Saudi student. As a first specialized maritime academy in the Kingdom of Saudi Arabia such as the major of (management and operation of ports, marine navigation, and marine engineering major), these majors represent a significant anxiety in determining his career and choosing the right 
specialization appropriate for him. Studies indicate that the most important thing concerning the Saudi youths is the future and fear of failure, which occupy the third place after the healthrelated concerns. $(11: 18)$

The person who practices sports activities is characterized by special preparations and capabilities in the physical, mental, psychological, and social aspects, as well as his social trends, tendencies, relations, and activities he practiced. All of these help to get rid of the anxiety that arises in his life. These aspects make him aware of his abilities and plan his future because he knows the value of himself. This subject has not been studied in this filed according to the researcher's knowledge. This prompted the researcher to study the subject to identify the personality traits and the concern of the future. He also aims to identify the relationship between practitioners and non-practitioners of sports activities so that we can guide young people in the light of the research results.

\section{Objectives}

The research aims to identify whether there are differences in both the level of personality traits and the level of professional future concern among practicing and nonpracticing students of sports activities.

\section{Hypotheses}

There are statistically significant differences at the level of personality traits and the level of professional future anxiety among practicing and non-practicing students of sports activities

\section{Research Terms}

\section{Traits:}

"Sima (trait), in the Arabic language, means a man (characterized by) a feature (trait) recognized by," (7: 722); in psychology, it means "relatively constant aspect of distinctive behavior of an individual." (1:117)

Trait refers to the distinctive attribute of person to behave a certain behavior." (5: 105)

\section{Personality:}

It is the dynamic organization within the individual of all physical and psychological systems, which determines the methods person uses to adapt to the environment. (10:131)

\section{Future Anxiety:}

It is the feeling of disturbance, tense, and distress when soundly thinking of it, and having a sense that life is not worthwhile with the loss of a sense of security and peace of mind about the future. (16:15); (21:5)

\section{Professional Future Anxiety:}

It is a state of tension and pessimism felt by a university student due to the scarcity of job opportunities after graduation. (9: 19) 


\section{Research Procedures}

\section{Exploratory Study}

The researcher conducted a pilot experiment on a sample of the same research community of 30 students from the Arab Academy for Maritime Studies in Jeddah from $03 / 14 / 2015$ to $03 / 17 / 2015$ for the purpose of:

- selecting the sample, by which the study can be conducted,

- Ensuring the clarity of the language adopted, and the lack of ambiguity in the words,

- The appropriateness of the terms of the psychological scales used for the research sample compared to the students level, and

- Identifying the time needed and consumed by students to answer.

\section{Exploratory Study Results}

- Reformulating some of the terms and phrases of professional future anxiety scale in order to facilitate its understanding by students,

- The segmentation of some compound phrases for simplification.

- Benefiting from the students' answers with respect to the selection of study majors and their correlation to the labor market, and

- $\quad$ Recognizing the students' need at this particular stage to the direction and guidance.

\section{Fundamental Study}

The researcher conducted the basic experience from 04/05/2015 to 04/26/2015

\section{Methodology}

The researcher used the descriptive approach with survey studies due to its appropriate nature to the research problem.

\section{Research Sample and Community}

The researcher has identified the research community represented by the students of $4^{\text {th }}$ and $5^{\text {th }}$ levels of the Arab Academy for Maritime Studies in Jeddah, Saudi Arabia. The sample consisted of 30 students of the $5^{\text {th }}$ level and 230 students of the $4^{\text {th }}$ level, of the academic year 2014- 2015.

The researcher selected the sample intentionally from the defined community as follows:

Fifty (50) students practicing in sports activities, 50 students non-practicing in sports activities, representing $45.5 \%$ of the research community, after excluding 30 students for exploratory study from the same research community. 


\section{Research Tools}

\section{Freiburg Personality Scale}

Prepared by Dr. Mohammad Hassan Allawi (Arabic Version). It consists of eight dimensions, including 56 phrases, answered by the respondent (yes) or (no). The researcher used this test, as it is easy to be applied and reliable; in addition, it did not take time to answer. The lowest degree can be obtained by the respondent in any of the personality dimensions measured by this test is 7 , and the highest degree is 14 , because each dimension contains 7 clauses. To give an answer confirming the dimension, the sample is given two degrees, but the opposite is given only one degree. Therefore, we can determine the degree of 10-11 as a middle rate, the degree of 7-10 as a low-grade, and 11-14 as a high degree of personality dimensions measured by the test. (3:310), (Annex 1)

To construct the future anxiety scale, the researcher has conducted the following:

After reviewing the research and studies that have addressed the subject of anxiety and future anxiety in general, such as the scale of future anxiety conducted by Shoukair (2005), future anxiety scale by Zaleski (1996)and the scale of future anxiety by the students of the University of Kuwait, Al-Ansari (2003), the researcher realized that many clauses in all of them do not fit with the variable to be measured within the research procedures. This is because these studies measured the future anxiety in more different areas and communities from the current research community. The interview was conducted with the students in order to make the scale phrases derived from Saudi Arabia environment in addition to relying on some phrases in some studies that have a relationship with the professional future anxiety. We found that its phrases are suitable for the design of professional future anxiety scale. This resulted in the preparation and drafting of the scale, which consists of 36 phrases, comprising 10 positive phrases, and 26 negative phrases. (21: 10); (23:165); (2), (Annex 2)

The following table indicates the phrases numbers and trends:

Table (1) indicates the numbers and direction of phrases in professional future anxiety form.

\begin{tabular}{cllc}
\hline Scale & \multicolumn{1}{c}{ Negative Phrases } & \multicolumn{1}{c}{ Positive Phrases } & Total \\
\hline & $20,15,14,11,28,24,22$, & $12,10,9,8,7,6,5,4,3,2$, & 36 \\
Professional Future Anxiety Scale & $21,30,29$ & $17,16,33,32,31,27,36$, & \\
& & 35,34 & \\
\hline Total & 10 & 26 & 36 \\
\hline
\end{tabular}

How to apply and correct the form

The student is asked to make good reading of the form phrases and answer with mark $(\sqrt{ })$ in front of the appropriate answer.

The points of scale form has been calculated as the following:

( $\sqrt{ })$ Applied: One point (1) 
$(\sqrt{ })$ Sometimes: Two points $(2)$

( $\sqrt{ })$ Not Applied: Three points (3)

It should be noted that the points are reflected when the phrase is formulated in a negative way. The test scores rang between (36-108). The researcher has established a neutral zone between the high and low levels of scale scores by adding the value of the standard deviation, included between of the exploratory study sample to theoretical mean value to get a top score for the neutral zone (mean). He earned, on the other hand, a minimum score for this zone by subtracting the value of the standard deviation from the theoretical mean. All scores exceeding these limits indicate the high level, while the score less than these limits indicate a low level. The least score can be obtained in any dimensions is 36 , the highest score 108, and standard deviation 1.16. The score of 36-71 indicates Weak, the score of 71-73 Average, the score of 73-108 High. (13: 506-527)

Scale Scientific Foundations

\section{Reliability}

The researcher has verified the reliability of future anxiety scale through re-testing method.

Reliability with internal consistency coefficient (Cronbach's alpha)

The researcher has used the (Cronbach's alpha) coefficient of internal consistency. This indicates that the scale is homogeneous, which means that all paragraphs measure a general variable. This reason stimulates the researcher to use this type of reliability.

\section{Reliability with Split-Half Method}

Reliability with Split-Half Method was extracted on the total sample. Table (2) demonstrates the reliability coefficient with the three mentioned methods of personality scale and professional future anxiety scale:

Table (2) Reliability Coefficient of future anxiety scale of retesting, internal consistency, and Split-Half methods of personality scale and future anxiety scale

\begin{tabular}{lccc}
\hline Scale & $\begin{array}{c}\text { Reliability } \\
\text { coefficient value, re- } \\
\text { testing }\end{array}$ & $\begin{array}{c}\text { The value of internal } \\
\text { consistency reliability } \\
\text { coefficient (Cronbach's } \\
\text { alpha) }\end{array}$ & $\begin{array}{c}\text { The value of Split-Half } \\
\text { reliability coefficient, } \\
\text { Spearman \& Brown }\end{array}$ \\
\hline Personality Scale & 0.942 & 0.934 & 0.912 \\
\hline $\begin{array}{c}\text { Professional Future Anxiety } \\
\text { Scale }\end{array}$ & 0.980 & 0.919 & 0.872 \\
\hline
\end{tabular}

Table (2) the reliability of personality scale and future anxiety scale where the value of reliability coefficient ranged between 0.872-0.980 indicating a high degree of reliability for both scales.

\section{Scale Validity}


The researcher has conducted discriminatory validity and internal consistency, which are based on the extraction of paragraphs relationship to the total. The research results indicate the following:

Table (3) the correlation coefficients of Personality scale and professional future anxiety scale

\begin{tabular}{lcl}
\hline \multicolumn{1}{c}{ Scale } & Calculated Correlation Coefficient & Sig. \\
\hline Personality Scale & 0.542 & Significant \\
\hline Professional Future Anxiety Scale & 0.612 & Significant \\
\hline
\end{tabular}

at the significance level $(\alpha \leq 0.05)$ and the degree of freedom (3)

The previous table results indicates that the coefficients of internal consistency validity between sub-score and the total score are statistically acceptable coefficients and refer to the extent the two scales have of an acceptable amount of validity.

The comparison of extreme groups (discriminatory validity)

The researcher has put the scores of rationing sample in descending order of each item of both scales. The scores have been divided into upper and lower parties. The highest $(27 \%)$ of the scores and the least $(27 \%)$ of the individuals' scores on both scales have been taken. The means, standard deviations of the scores, and ( $\mathrm{t}$ ) value, and significance level test have been calculated as follows:

Table (4) indicates the means, standard deviations, and $(t)$ value of personality scale and professional future anxiety scale

\begin{tabular}{lccc}
\hline \multicolumn{1}{c}{ Scale } & $($ t) value & Sig. Level & Sig. \\
\hline Personality Scale & 7.80 & 0.01 & Significant \\
\hline Professional Future Anxiety Scale & 10.27 & 0.01 & Significant \\
\hline
\end{tabular}

The previous table indicates that the means and standard deviations of Third or Upper Quartile of scores in the two scales are higher than the arithmetic means and standard deviations of the First or Lower Quartile. (t) value was also significant at the level (0.01), which indicates that both scales have the ability to distinguish between both levels.

\section{Results and Discussion}

Presentation and discussion of the hypothesis, which reads as follows:

"There are statistically significant differences at the level of personality traits and the level of professional future anxiety among practicing and non-practicing students of sports activities."

Table (5) illustrates the arithmetic mean, the significance level of personality traits according to Freiburg personality scale among practicing and non-practicing students of sports activities under discussion 
Table (5) The levels of personality traits according to Freiburg personality scale among practicing and non-practicing students of sports activities under discussion

\begin{tabular}{|c|c|c|c|c|c|c|}
\hline \multirow{2}{*}{ No. } & \multirow{2}{*}{ Trait } & \multirow{2}{*}{$\begin{array}{l}\text { Paragraphs } \\
\text { Number }\end{array}$} & \multicolumn{2}{|c|}{$\begin{array}{c}\text { Practicing students of } \\
\text { sports activities }\end{array}$} & \multicolumn{2}{|c|}{$\begin{array}{c}\text { Non-practicing students } \\
\text { of sports activities }\end{array}$} \\
\hline & & & $\begin{array}{l}\text { Arithmetic } \\
\text { mean }\end{array}$ & Sig. Level & $\begin{array}{l}\text { Arithmetic } \\
\text { mean }\end{array}$ & Sig. Level \\
\hline 1 & Nervousness & 7 & 9.11 & Low & 10.12 & Average \\
\hline 2 & Aggressiveness & 7 & 9.45 & Low & 11.02 & High \\
\hline 3 & Depressive & 7 & 7.95 & Low & 12.45 & High \\
\hline 4 & Excitability & 7 & 10.37 & Mean & 11.37 & High \\
\hline 5 & Social & 7 & 12.56 & High & 9.61 & Low \\
\hline 6 & Calmness & 7 & 10.42 & Mean & 10.35 & Average \\
\hline 7 & Control & 7 & 11.93 & High & 10.85 & Average \\
\hline 8 & Prevention & 7 & 8.64 & Low & 10.32 & Average \\
\hline
\end{tabular}

* Score (7-10) is low, (10-11) is a middle rate, and (11-14) is a high score

Table (5) indicates that level of (nervousness, aggressive, depressive and prevention) trait is low, and the level of (social and control) trait is high, while the level of (excitability and calmness) trait is average among practicing students of sports activities. The level of (social) trait is low, and the level of (aggressive, depressive and excitability) is high.

These dimensions indicate:

- The high level of (nervousness) dimension distinguishes individuals who suffer from physical, kinetic neurological and psychological disorders,

- The high level of (Aggressive) dimension distinguishes individuals who are engaged in aggressive physical or verbal actions, such as attack, the lack of calm and not control themselves,

- The high level of (excitability) dimension distinguishes individuals who have a high level of excitability, severity of tension, a weak ability to confrontation, and lack of patience and anger,

- The high level of (Depressive) dimension distinguishes individuals with depression, a sense of dissatisfaction and unhappiness, fear and a tendency to attack the self,

- The high level of (Social) dimension distinguishes individuals who are able to interact with others and characterized by fun, active and promptitude,

- The high level of (Calmness) dimension distinguishes individuals with self-confidence and lack of confusion and stay away from aggressive behavior, 
- The high level of (Control) dimension distinguishes individuals with aggressive reactions , whether verbal or physical, the tendency to use violence and the attempt to impose their views on others,

- The high level of (Prevention) dimension distinguishes individuals of lack of ability impose their views on others.

Table (6) illustrates the arithmetic mean and the level of professional future anxiety among practicing and non-practicing students of sports activities, under discussion.

Table (6) the level of professional future anxiety among practicing and non-practicing students of sports activities.

\begin{tabular}{lcc}
\hline \multicolumn{1}{c}{ Sample } & Arithmetic mean & Significance level \\
\hline Practicing students of sports activities & 72.87 & Average \\
\hline Non-practicing students of sports activities & 76.48 & High \\
\hline
\end{tabular}

* The score of (36-71) indicates Weak, (71-73) Average, (73-108) High.

Table (6) indicates that the level of professional future anxiety among practicing students of sports activities is average, while the level of professional future anxiety among nonpracticing students of sports activities is high.

Table (7) demonstrates the arithmetic mean and standard deviation of personality traits scale for both the dimension and scale of professional future anxiety, calculated $(\mathrm{t})$ value, and the significance level.

Table (7) The arithmetic mean and standard deviation of personality traits scale for both the dimension and scale of professional future anxiety, calculated $(t)$ value, and the significance level

\begin{tabular}{|c|c|c|c|c|c|c|}
\hline Variables & \multicolumn{2}{|c|}{$\begin{array}{c}\text { Practicing } \\
\text { students of } \\
\text { sports activities }\end{array}$} & \multicolumn{2}{|c|}{$\begin{array}{c}\text { Non-practicing } \\
\text { students of } \\
\text { sports activities }\end{array}$} & $\begin{array}{c}\text { Calculated }(t) \\
\text { value }\end{array}$ & $\begin{array}{c}\text { Significance } \\
\text { level }\end{array}$ \\
\hline \multirow{2}{*}{ nervousness trait } & $\mathrm{AM}$ & 9.11 & $\mathrm{AM}$ & 10.12 & \multirow{2}{*}{1.43} & \multirow{2}{*}{ Insignificant } \\
\hline & SD & 1.16 & SD & 1.21 & & \\
\hline \multirow{2}{*}{ Aggressive trait } & $\mathrm{AM}$ & 9.45 & $\mathrm{~S}$ & 11.02 & \multirow{2}{*}{1.85} & \multirow{2}{*}{ Insignificant } \\
\hline & SD & 1.53 & SD & 1.65 & & \\
\hline \multirow{2}{*}{ Depressive trait } & $\mathrm{AM}$ & 7.95 & $\mathrm{AM}$ & 12.45 & \multirow{2}{*}{2.22} & \multirow{2}{*}{ Significant } \\
\hline & SD & 1.7 & SD & 1.27 & & \\
\hline \multirow{2}{*}{ Excitability trait } & $\mathrm{AM}$ & 10.37 & $\mathrm{AM}$ & 11.37 & \multirow{2}{*}{1.92} & \multirow{2}{*}{ Insignificant } \\
\hline & SD & 1.18 & SD & 1.24 & & \\
\hline \multirow{2}{*}{ Social trait } & $\mathrm{AM}$ & 10.56 & $\mathrm{AM}$ & 9.61 & \multirow{2}{*}{3.13} & \multirow{2}{*}{ Significant } \\
\hline & SD & 2.1 & SD & 1.85 & & \\
\hline \multirow{2}{*}{ Calmness trait } & $\mathrm{AM}$ & 10.42 & $\mathrm{AM}$ & 10.35 & \multirow{2}{*}{1.54} & \multirow{2}{*}{ Insignificant } \\
\hline & SD & 1.6 & SD & 1.75 & & \\
\hline \multirow{2}{*}{ Control trait } & $\mathrm{AM}$ & 11.93 & AM & 10.85 & \multirow{2}{*}{1.74} & \multirow{2}{*}{ Insignificant } \\
\hline & SD & 1.84 & SD & 1.58 & & \\
\hline \multirow{2}{*}{ Prevention trait } & $\mathrm{AM}$ & 8.64 & $\mathrm{AM}$ & 10.32 & \multirow{2}{*}{2.12} & \multirow{2}{*}{ Significant } \\
\hline & SD & 1.3 & SD & 1.53 & & \\
\hline
\end{tabular}




\begin{tabular}{lccccccc}
\hline \multirow{2}{*}{ Professional Future Anxiety Scale } & AM & 72.87 & AM & 76.48 & \multirow{2}{*}{4.09} & \multirow{2}{*}{ Significant } \\
\cline { 2 - 5 } & SD & 4.51 & SD & 6.21 & & \\
\hline
\end{tabular}

* tabulated $(\mathrm{t})$ value at a significance level of (0.05), which estimates (1.96)

Table (7) The value of statistical significance in every aspect of personality traits among the practicing and non-practicing students of sports activities After identifying the values of arithmetic means, standard deviations, and calculated $(\mathrm{t})$ value compared with tabulated ( $\mathrm{t}$ ) value, it is indicated that there is no significance between practicing, and non-practicing students of sports activities in both (nervousness, aggressive, excitability, control, and calmness trait). While there is significance between them in (depressive, social, and prevention) trait, and the decline in the values of (nervousness, aggressive, excitability, and control) trait. The researcher attributes this result to the age of youths, sample research, in addition to the nature of school system that governs the individual commitment to the internal regulations, government supervision, good moral, and the best way to deal with students, as well as professors. The individual, therefore, takes stock of himself for any action before society. This is due to the fear of deviancy or improper conduct that leads to penalty against him or bad perception from the community or administration. Thus, their conduct tends toward proper human and social values of the social provisions and traditions. As the research sample is university students, who gained a degree of mental, social and emotional growth that stimulates them to be more socially and psychologically adaptable, They comply with the trends in society and become more compliant to the values of society and its customs and traditions (17:260)

For control trait, it is linked to the values of the aggressive trait. As the aggressive was low and insignificant, the control trait was also low and insignificant, that is, that there is a close correlation between the control and aggressive trait. Allawi (1998) conclude this result indicating, "Those who have a high degree of control trait are characterized by aggressive reactions, whether verbal, physical, imaginary, or distrust in the others and lack of confidence, the tendency of power, using violence, and trying to impose their attitudes on others." (5:80) That means that there is correlation between them, if one of them declines, and the other does, and vice versa. The same case with calmness trait, but the process is the opposite, if the aggressive declines, calmness becomes high and vice versa. As the aggressive trait was low among the sample, the calmness trait was high. Allawi (1998) indicated that those who have a high degree of calmness trait are characterized by "confidence and lack of confusion or attention deficit, attention difficulty, mild mood, optimism, keep away from aggressive behavior, and go to work. (5:80) This refers to the inverse relationship between calmness trait, aggressive, nervousness, and excitability traits. This is an indicator to the cohesion of the moral, social and religious values among the academy students and their commitment to good ethics.

The same table indicates that there is significance among the practicing and nonpracticing students of sports activities in depressive, social and prevention traits. The social trait was in favor of practicing students of sports activities, while depressive and prevention traits were in favor of non-practicing students of sports activities. For the social trait, the researcher attributes this result to the nature of athletes' practice and their social interaction with each other. Some studies have confirmed that the athlete is easily intercourse and a lover of people and significantly sociable. One of these studies conducted by Mohamed Hassan Allawi (4 : 312) indicating that social trait "is the ability to interact with others and attempt to get closer to people 
and the speed of form friendships, fun, vitality, activity and the acquisition of a large circle of friendship", (4: 149). Practicing sports that require teamwork and activity actually strengthens social ties. Playing in general and sports in particular are actually a social phenomenon dominated by cooperation in order to achieve a particular goal. This is what led to distinguish athletes from their peers that are restricted by the nature of traditional lecture in theoretical halls. Even if they have practical lectures, they are limited in the computer labs, there is no interaction with each other, and within the closed framework.

For depressive trait, it is low among practitioners and in favor of non-practitioners. This is due to the "general practice of sport and various sports games, which reduce depressive, broadcast the spirit of mutual understanding, boost morale, and develop the will, courage, and self-confidence $(4: 80)$. This means that there is an inverse relationship between high social interaction among athletes and the value of depressive. The same case is between social trait and prevention trait. Those who have a high degree of prevention trait have (a lack ability to make decisions quickly and weakness in immediate resolution of situations, especially the social attitudes, weakness in interaction and dealing with others, shyness, and confusion). (4:80) This led to the rise in the value of social trait and the decrease in the value of prevention trait among the athletes.

Table (7) indicates that there are statistically significant differences in the professional anxiety scale in favor of non-practicing students of sports activities. The researcher attributed those results to the different personality traits of practicing and non-practicing students of activities. "The personality can play an important role. The researchers noted that individuals who do not show a lot of appreciation and with weak adaptive skills show symptoms of anxiety more than others do. In addition, life experiences may affect the individual's sensitivity to anxiety". (19:204)

This anxiety may result from life situations that the environment plays an important role in its occurrence as well as its aggravation, such as stressful life that causes resentment and indirect stresses linked to the conflict between cultural pressures and modern environment. (6: $280,281) ;(8: 188)$

Hassanein (2000) suggested that the group of traits that those of future anxiety and professional future anxiety characterized with is pessimism. This is because the one who fears of the future expects only evil, exploitation of social relations to secure the individual's future, the withdrawal of constructive activities without risk, lack of confidence in anyone, leading to a collision with the others, taking preventive measures in order to maintain the status quo rather than risking in order to increase opportunities in the future, a strong concentration on the current events and escape into the past, the introversion and the emergence of sadness, doubt and hesitation marks, the fear of social and political changes expected to occur in the future, hardness of opinion and intransigence, the emergence of agitation for the lowest reasons, maintaining the routine and traditional conditions in dealing with life situations, and passively waiting for what may be happened. (12: 19)

Most of those traits do not apply to sports personality traits. Sports activities distinguish athletic personality with some features that differ in kind and degree from those features that distinguish non-sporting personality as each sports activity has a private nature. (10:136) 


\section{Conclusions and Recommendations}

\section{Conclusions}

1. The effectiveness of professional future anxiety scale concluded by the researcher,

2. There are no differences between practicing and non-practicing students of sports activities in the level of (nervousness, aggressive, excitability and calmness, and control) traits,

3. There are differences between practicing and non-practicing students of sports activities for favor of the practitioners in the level of (social trait

4. There are differences between practicing and non-practicing students of sports activities for favor of non-practitioners in the level of (depressive and prevention) traits. ), and the level of professional future concern

\section{Recommendations}

1. It is necessary to focus on the personality aspects through the development of personality traits when rehabilitating and teaching students,

2. It is necessary to measure personality traits and the level of anxiety among students, especially when they apply for the Academy to install the level of personality traits as well as conducting physical tests to reflect a clear picture of the level of personality traits of the students,

3. Sports and psychological specialist should be used, and coordination among him, the teachers, and administration is required for the success of educational processes.

4. The stimulation of excitement among students should be increased and the exploitation of young people energies and encourage them to participate in sports activities,

5. It is necessary to guide the students to be confident, believe in themselves and in their abilities to make the effort, perseverance in work and struggle for success,

6. Appropriate university environment in the academy should be provided, thus contributing to reduce the students' anxiety, and

7. Similar research should be conducted to find a relationship between personality traits of athletes, non-athletes, and other variables. 


\section{References}

1. Aakel, Fakher, (1977): Glossary of Psychology, Beirut, Dar Alilm Lilmalayin,.

2. Al-Ansari, Bader Mohamed, (2003): The Differences between Male and Female Students at Kuwait University in anxiety and depression, Ain Shams University, The Volume of 10th International Conference of the Psychological Counseling Center.

3. Allawi, Mohamed Hassan \& Radwan, Mohamed Nasreddin (1987): Psychological Tests and Skills in the Sports Field, Cairo, Dar Al Fikr El Arabi,.

4. Allawi, Mohamed Hassan, (1998): Encyclopedia of Psychological Tests for Athletes, 1st Ed., Cairo, Markz el-Ketab Publishing,.

5. Allawi, Mohamed Hassan, (1998): Introduction to Sports Psychology,1st Ed., Cairo, Markz el-Ketab Publishing,.

6. Al-Mutairi, Suhail Maasoma, (2005): Mental Health, Concept and Perturbations, 1st Ed., Amman, Al-Falah Bookshop,.

7. Al-Razi, Mohamed Abu Bakr, (1983): Mukhtar Asahah (Wasim Entry), Beirut, Dar ElKutub Al-Arabi Printing,.

8. Al-Sayed, Magda Ebeid, (2008): Psychological Stress, Its Problems and Impact on Mental Health, 1st Ed., Amman, Jordan, Dar al-Waffa Publishing \& Distribution,.

9. El-Hudeeby, Mustafa Abdul Mohsen, (2007): Effectiveness of Religious Psychological Counseling in Reducing Professional Future Anxiety among the Students of the Faculty of Education in Asyut, unpublished Master Thesis, University of Asyut,.

10. Fawzi, Ahmad Amin, (2003): The principles of Sports Psychology (Concepts, Theories). 1st Ed., Cairo, Dar Al Fikr El Arabi,.

11. Hafiz, Ahmed Khairy, (1989): Common Fears among Samples of Students from Saudi Arabia. Journal of Psychology, 9th Ed.,

12. Hassanein, Ahmed Mohamed, (2000): The Future Anxiety and Test Anxiety in Their Relationship with Some Psychological Variables among a Sample of 2nd Grade Secondary Students, Unpublished Master Thesis, Faculty of Arts, University of Minya, .

13. Jassim, Amer Saeed (2008): Construction and Application of Personality Traits Scale to Football Players, Journal of Human Sciences, 2nd Ed. 
14. Mahrous, Yasser Mustafa, (2008): The Personality Traits Distinctive to Bodies Patterns of Practicing and Non-practicing College Students, Faculty of Physical Education for Boys in Al-haram, Helwan University, Ph.D. Thesis.

15. Mansouri, Ali Omar, (1980): Sport for All, Egypt, Dar al-Waffa Publishing,.

16. Masoud, Sanaa Munir, (2006): Some Variables Associated with Future Anxiety, Master Thesis (Unpublished), Faculty of Education, Cairo, Egypt,.

17. Mohamed, Magdi Ahmed, (2006): Educational Psychology between Theory and Practice, Alexandria, Dar El-Marefa El-Gameya,.

18. Pullianinen, Harry, (1991): "The Changing Parent-Child Relationship, Self-Esteem, and Intelligence as Determinants of Orientation to the Future during Early Adolescence", Journal of Adolescence, Vol $14 \operatorname{No}(1)$.

19. Riad, Saad, (2005): Personality, Types, Diseases and Time to Deal with It, 1st Ed., Cairo, Eqraa Foundation Printing.

20. Samir, Hani Ahmed, (2007): Some Personality Traits Among Practicing and Nonpracticing Students of Sports Activities at the University, Ain Shams University, Master Thesis, Department of Psychology and Social Studies, The Institute of Childhood Postgraduate Studies.

21. Shoukair, Zainab Mahmoud, (2005): Professional Future Anxiety Scale. Cairo, AngloEgyptian Bookshop,.

22. Trommsdorff, Gisela, (1999): "A Longitudinal Study of Adolescents futures orientation", Journal of Youth and Adolescence, Vol 8 No 2 Jun 1999.

23. Zaleski, Zbigniew (1996): Future Anxiety: Concept, Measurement, And Preliminary Research, Personal Individual Difference. Elsevier Science, 21 (2), 
